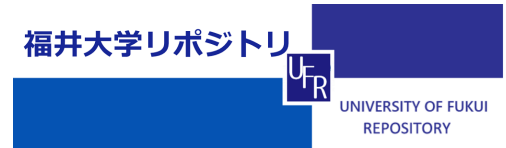

The mi crowave spect rum of a new phosphor us- bear i ng r adi cal $\mathrm{CH} 2 \mathrm{P}(2 \mathrm{~B} 2)$

\begin{tabular}{|l|l|}
\hline 著者 & SAl TO Shuj i, YAMAMOTO Sat oshi \\
\hline $\begin{array}{l}\text { j our nal or } \\
\text { publ i cat } \mathrm{i} \text { on } \mathrm{t} \text { i t l e }\end{array}$ & Journal of Chemi cal Physi cs \\
\hline vol une & 111 \\
\hline number & 17 \\
\hline page $\mathrm{r}$ ange & $7916-7920$ \\
\hline year & $1999-11$ \\
\hline URL & ht t $\mathrm{p} / /$ hdl . handl e. net /10098/1530 \\
\hline
\end{tabular}




\title{
The microwave spectrum of a new phosphorus-bearing radical $\mathrm{CH}_{2} \mathrm{P}\left({ }^{2} \mathrm{~B}_{2}\right)$
}

\author{
Shuij Saito \\ Institute for Molecular Science, Myodaiji Okazaki 444-8585, Japan \\ Satoshi Yamamoto \\ Department of Physics, The University of Tokyo, Bunkyo-ku, Tokyo 113-0033, Japan
}

\begin{abstract}
The microwave spectrum of the $\mathrm{CH}_{2} \mathrm{P}$ radical in its ${ }^{2} B_{2}$ ground electronic state was detected for the first time using a source-modulated spectrometer equipped with a free-space cell. The $\mathrm{CH}_{2} \mathrm{P}$ radical was generated in the cell by a dc-glow discharge in a mixture of $\mathrm{PH}_{3}, \mathrm{CH}_{4}$, and $\mathrm{He}$, and its isotopic species, $\mathrm{CD}_{2} \mathrm{P}$, in a mixture containing $\mathrm{CD}_{4}$ instead of $\mathrm{CH}_{4}$. Forty four $a$-type $R$-branch rotational transitions of $\mathrm{CH}_{2} \mathrm{P}$ were measured for the transitions $N=8-7$ to $N=12-11$ with $K_{a}=0$ to 5 in the frequency region of $260-400 \mathrm{GHz}$, for which fine and hyperfine structures due to the phosphorus and hydrogen nuclei were resolved. For $\mathrm{CD}_{2} \mathrm{P}, 39$ rotational transitions from $N=9-8$ to $\mathrm{N}$ $=13-12$ with $K_{a}=0$ to 4 were measured in the $240-355 \mathrm{GHz}$ with fine structure and phosphorus hyperfine structure. Molecular constants of $\mathrm{CH}_{2} \mathrm{P}$, including the fine structure constants and hyperfine coupling constants due to both the nuclei of $\mathrm{P}$ and $\mathrm{H}$, were precisely determined by least-squares metbods from 158 observed spectral lines. Those of $\mathrm{CD}_{2} \mathrm{P}$ were similarly obtained from 70 observed spectral lines. The rotational constants of both species were used to derive the molecular structural parameters for $\mathrm{CH}_{2} \mathrm{P}: r_{0}(\mathrm{CP})=1.6576(28) \AA, r_{0}(\mathrm{CH})=1.0912(61) \AA$, and $\angle \mathrm{HCH}=115.96(96)^{\circ}$. The spin densities of unpaired electrons on the $\mathrm{P}$ and $\mathrm{H}$ nuclei were estimated from the hyperfine coupling constants, and found to be consistent with the molecular structure determined.
\end{abstract}

\section{INTRODUCTION}

Many simple and fundamental phosphorus-bearing molecules, composed of hydrogen, carbon, and/or oxygen, have been postulated to exist in the gas phase, because of the multi-valence feature of phosphorus. However, many of them are unknown spectroscopically as well as chemically, and their chemical and physical properties have been uncharacterized.

Recentiy we studied two such examples, $\mathrm{H}_{3} \mathrm{PO}$ (Ref, l) and $\mathrm{H}_{2} \mathrm{PO},{ }^{2}$ by microwave spectroscopy. Both molecules had previously not been studied in the gas phase by any highresolution spectroscopic methods. For the $\mathrm{H}_{3} \mathrm{OP}$ chemical system several high-level and sophisticated $a b$ initio calculations had predicted that cis and trans $\mathrm{H}_{2} \mathrm{POH}$ (separated by a small energy difference of $0.3 \mathrm{kcal} / \mathrm{mol}$ ) are the most stable isomers and the third form, $\mathrm{H}_{3} \mathrm{PO}$, is located at an energy of $6.5 \mathrm{kcal} / \mathrm{mol}$ above the cis $\mathrm{H}_{2} \mathrm{POH}$ form. ${ }^{3}$ However, we found that the most stable form for the chemical system of $\mathrm{H}_{3} \mathrm{OP}$ is a symmetric top form, $\mathrm{H}_{3} \mathrm{PO}$, ${ }^{1}$ which was efficiently generated in a discharge mixture of $\mathrm{PH}_{3}, \mathrm{CO}_{2}$, and $\mathrm{H}_{2}$. We also found that a new stable $\mathrm{H}_{2} \mathrm{PO}$ radical exists in the discharged $\mathrm{PH}_{3}$ and $\mathrm{CO}_{2}$ gas mixture. From the rotational constants for the $\mathrm{H}_{2} \mathrm{P}^{16} \mathrm{O}$ and $\mathrm{H}_{2} \mathrm{P}^{18} \mathrm{O}$ species the $\mathrm{PO}$ bond length was determined to be $1.4875(4) \AA^{2}$. This result was in contrast with with sophisticated quanturn chemical calculations which predicted the optimized $\mathrm{PO}$ bond length of $\mathrm{H}_{2} \mathrm{PO}\left(\tilde{X}^{2} A^{\prime}\right)$ and were found to differ significantly at the various level of calculations used; a single PO bond length of $1.589 \AA$ was calculated at the HF/6-31G** level and a double PO bond length of $1.495 \AA$ at UMP2/6-31G** ${ }^{+} \mathrm{A}$ structural difference among $\mathrm{HPO}, \mathrm{H}_{2} \mathrm{PO}$, and $\mathrm{H}_{3} \mathrm{PO}$ was explained by the fact that the PO bond in HPO is a typical double bond made up of one $p_{\sigma}$ bond and one $p_{\pi}$ bond, whereas the $\mathrm{PO}$ bond in $\mathrm{H}_{2} \mathrm{PO}$ and $\mathrm{H}_{3} \mathrm{PO}$ is a resonance hybrid between a single and triple bond structure or a dative single bond augmented by $\pi$ back donation to the vacant $d$ orbital of $\mathrm{P}$ from the $\mathrm{O}$ lone pairs. ${ }^{1} \mathrm{~A}$ full characterization of $\mathrm{H}_{3} \mathrm{PO}$ and $\mathrm{H}_{2} \mathrm{PO}$ has been substantiated by high-resolution microwave spectroscopy.

Furthermore very few spectroscopic and theoretical studies have been caried out made on transient $\mathrm{CP}$-bond-bearing molecules. We also studied two such examples HCCP (Ref. 5) and $\mathrm{CH}_{2} \mathrm{CP}$ (Ref. 6) by microwave spectroscopy. Based on the spin densities of $\mathrm{HCCP}$ derived from its observed hyperfine coupling constants, we concluded that the molecular structure of HCCP could be explained by a linear combination of two canonical configurations of phospho-allene and phosphorene forms with an approximate weight of three to one. The molecular structure of HCCP is quite different from that of the corresponding nitrogen-bearing radical HCCN, for which was suggested a canonical form composed of allene and carbene with a weight of two to one. ${ }^{7}$ Similarly the molecular structure of $\mathrm{CH}_{2} \mathrm{CP}$ was found to have a $\mathrm{C}-\mathrm{C}$ double bond and a relatively long $\mathrm{C}-\mathrm{P}$ triple bond. ${ }^{6} \mathrm{Molecu-}$ lar struciural characterization of HCCP and $\mathrm{CH}_{2} \mathrm{CP}$ has been also demonstrated by microwave spectroscopy.

Another important $\mathrm{CP}$ bond-bearing molecule is the $\mathrm{CH}_{2} \mathrm{P}$ radical which has not been studied in either the gas or solid phase by any spectroscopic methods. Only one $a b$ initio calculation study ${ }^{8}$ was reported on this radical, predicting 
that $r(\mathrm{CP})=1.707 \AA, r(\mathrm{CH})=1.079 \AA$, and $\angle \mathrm{HCP}$ $=122.1^{\circ}$ at the MPASDTO/6-31G $(d, p)$ level of theory. The nitrogen analog of $\mathrm{CH}_{2} \mathrm{P}, \mathrm{CH}_{2} \mathrm{~N}$, was studied by microwave spectroscopy, and concluded to have a structure with a relatively short $\mathrm{CN}$ bond intermediate between a double $\mathrm{C}=\mathrm{N}$ bond and a triple $\mathrm{C} \equiv \mathrm{N}$ bond, which is consistent with spin densities on $\mathrm{H}$ and $\mathrm{N}$ derived from its hyperfine coupling constants. ${ }^{9}$ Later, $\mathrm{CH}_{2} \mathrm{~N}$ was found to exist in a cold dark molecular cloud TMC-1 (Cyanopolyyne Peak) on observation of its lowest $a$-type $R$-branch transition $1_{01}-0_{00}$ with the $12 \mathrm{~m}$ Kitt Peak telescope of NRAO. ${ }^{10}$ The fractional abundance was derived to be very small in space $\left(1.5 \times 10^{-11}\right)$ relative to that of hydrogen.

This paper presents the first gas-phase identification and characterization of $\mathrm{CH}_{2} \mathrm{P}$ by microwave spectroscopy. Molecular constants of $\mathrm{CH}_{2} \mathrm{P}$ and $\mathrm{CD}_{2} \mathrm{P}$ were determined with high precision, and were used to derive the molecular structure and spin density of $\mathrm{CH}_{2} \mathrm{P}$.

\section{EXPERMENT}

Spectral lines of $\mathrm{CH}_{2} \mathrm{P}$ were first measured by using a frequency-modulated microwave spectrometer at $\mathrm{Na}$ goya University ${ }^{11}$ and later at the lastiute for Molecular Science. ${ }^{12}$ The chenuical system used was a dc-glow discharge $(200 \mathrm{~mA})$ of a mixture of $\mathrm{PH}_{3}$ (10 m $\left.\mathrm{m}^{\text {Torr }}\right), \mathrm{CH}_{4}$ (15mTorr), and He(5 mTorr) in a 2 m-free space cell maintained at about $-180^{\circ} \mathrm{C}$. A set of fine and hyperfine-structure resolved spectral lines appeared at about every $33 \mathrm{GHz}$ and showed a typical $K$ structure feature of $a$-type $R$-branch rotational transitions. The $K_{a}=$ odd transitions showed a doublet pattern for a fine structure component, whereas the $K_{a}=$ even transitions showed a complicated pattern composed of several lines. The spectral line pattern and the chemical behavior made us conclude that the observed lines originated from a new phosphorus-bearing radical, $\mathrm{CH}_{2} \mathrm{P}$. The ground electronic state of $\mathrm{CH}_{2} \mathrm{P}$ was considered to have ${ }^{2} B_{2}$ symmetry, as implied by the ground electronic state of $\mathrm{CH}_{2} \mathrm{~N},{ }^{9}$ so that the hyperfine structures observed for the $K_{a}=$ even and odd transitions were well explained by the coupling scheme of $J=N+S, F_{1}=J$ $+I(\mathrm{P}), I(\mathrm{H})=I\left(\mathrm{H}_{1}\right)+I\left(\mathrm{H}_{2}\right)$, and $F=F_{1}+I(\mathrm{H})$. An example of the observed spectral pattern is shown in Fig. 1.

When $\mathrm{CD}_{4}$ was used instead of $\mathrm{CH}_{4}$ in the gas mixture, most of the $\mathrm{CD}_{2} \mathrm{P}$ rotational lines did not show hyperfine structure due to the deuterium nuclei. Only $K_{a}=1$ and 2 components of the $N=9-8$ transition showed broadened and unsymmetrical line shapes, and high $K_{a}$ components revealed partially resolved features which were too weak to be measured precisely. An example of such line shapes is shown in Fig. 2.

\section{ANALYSIS}

The observed spectral lines were analyzed using the following Hamiltonian for an asymmetric top radical in a doublet electronic state: ${ }^{13}$

$$
H=H_{\mathrm{rot}}+H_{\mathrm{sr}}+H_{\mathrm{mar}}(\mathrm{P})+H_{\mathrm{mbr}}(\mathrm{H} \text { or D }),
$$

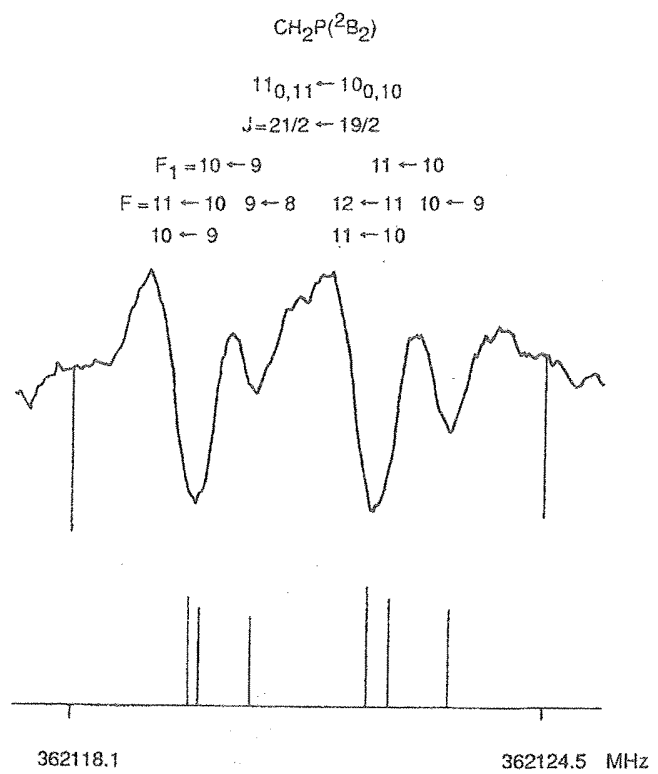

FIG. 1. The observed phosphorus and hydrogen hyperine structure of the $K_{a}=0$ rotational transition of $\mathrm{CH}_{2} \mathrm{P}: 11_{0,4}-10_{0,10}, J=21 / 2-19 / 2$. The lower stick diagran shows calculated hyperine structure with relative intensity. $\mathrm{CH}_{2} \mathrm{P}$ was produced by a $200 \mathrm{~mA}$ dc-glow discharge in a mixture of $\mathrm{PH}_{3}$ (10 mTorr), $\mathrm{CH}_{4}$ (15 mTorr), and $\mathrm{He}(5$ mTorr). The integration time was $20 \mathrm{~s}$.

$$
\begin{gathered}
\mathrm{CO}_{2} P\left(\mathrm{~B}_{2}\right) \\
1138+10_{37} \\
J=21 / 2-19 / 2 \\
F_{1}=11-10
\end{gathered}
$$
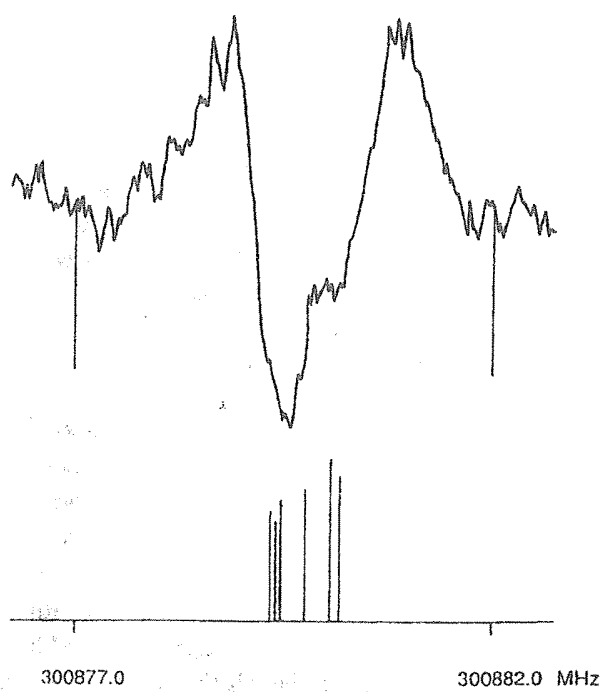

FIG. 2. The observed line shape of the $K_{t l}=3$ rotational transition of $\mathrm{CD}_{2} \mathrm{P}: 11_{38}-10_{37}, J=21 / 2-19 / 2, \quad F_{1}=11-10$. The lower stick diagram shows calculated deuterium $(I(D)=0.2)$ hypertine structure with relative intensity. The integration time was $40 \mathrm{~s}$. 
TABLE I. Some observed and calculated transition frequencies of $\mathrm{CH}_{2} \mathrm{P}^{\mathrm{a}}$

\begin{tabular}{|c|c|c|c|c|}
\hline$I^{t}-J$ & $F_{1}^{*}-F_{1}$ & $F^{\prime}-F$ & $v_{\text {obs }}$ & $\Delta \nu^{b}$ \\
\hline \multicolumn{5}{|c|}{$N_{K a k c}=11_{0,11}-10_{0,10}$} \\
\hline \multirow[t]{4}{*}{$23 / 2-21 / 2$} & $12-11$ & $13-12$ & 361948.859 & -0.042 \\
\hline & & $12-11$ & 361949.663 & $0.072^{c}$ \\
\hline & & $11-10$ & & \\
\hline & $11-10$ & & 361951.299 & $0.189^{\mathrm{C}}$ \\
\hline \multirow[t]{5}{*}{$21 / 2-19 / 2$} & $11-10$ & $12-11$ & 362122.537 & -0.022 \\
\hline & & $\begin{array}{c}11-10 \\
10-9\end{array}$ & 362123.533 & -0.003 \\
\hline & $10-9$ & $11-10$ & 362120.109 & $0.070^{\circ}$ \\
\hline & & $10-9$ & & \\
\hline & & $9-8$ & 362120.944 & $0.090^{c}$ \\
\hline \multicolumn{5}{|l|}{$11_{1,11}-10_{1,10}$} \\
\hline \multirow{2}{*}{$23 / 2-21 / 2$} & & $12-11$ & 357022.235 & 0.020 \\
\hline & & $11-10$ & 357023.304 & -0.028 \\
\hline \multirow[t]{2}{*}{$21 / 2-19 / 2$} & & $11-10$ & 357284.146 & -0.061 \\
\hline & & $10-9$ & 357285.176 & $0.117^{\circ}$ \\
\hline \multicolumn{5}{|l|}{$\begin{array}{l}11_{1,10}-10_{1,9} \\
23 / 2-21 / 2\end{array}$} \\
\hline $23 / 2-21 / 2$ & & $\begin{array}{l}12-11 \\
11-10\end{array}$ & $\begin{array}{l}367643.180 \\
367642.374\end{array}$ & $\begin{array}{r}0.026 \\
-0.042\end{array}$ \\
\hline \multirow[t]{2}{*}{$21 / 2-19 / 2$} & & $11-10$ & 367761.778 & -0.026 \\
\hline & & $10-9$ & 367760.248 & -0.017 \\
\hline \multirow{7}{*}{$\begin{array}{l}11_{2,10}-10_{2,9} \\
23 / 2-21 / 2\end{array}$} & & & & \\
\hline & $12-11$ & $13-12$ & 362278.403 & -0.012 \\
\hline & & $12-11$ & 362217.365 & $-0.445^{c}$ \\
\hline & & $11-10$ & 362209.135 & 0.037 \\
\hline & $11-10$ & $12-11$ & 362238.520 & $0.482^{c}$ \\
\hline & & $11-10$ & 362313.532 & 0.045 \\
\hline & & $10-9$ & 362292.276 & $0.163^{c}$ \\
\hline \multirow{5}{*}{$21 / 2-19 / 2$} & $11-10$ & $12-11$ & 362668.692 & $-0.144^{\mathrm{c}}$ \\
\hline & & $11-10$ & 362622.431 & $-0.110^{c}$ \\
\hline & & $10-9$ & 362564.121 & -0.013 \\
\hline & $10-9$ & $11-10$ & 362549.315 & -0.018 \\
\hline & & $10-9$ & 362559.652 & $-0.134^{\mathrm{c}}$ \\
\hline \multirow{7}{*}{$\begin{array}{l}11_{29}-10_{28} \\
23 / 2-21 / 2\end{array}$} & & $9-8$ & 362569.756 & 0.010 \\
\hline & $|2-1|$ & $13-12$ & 362829.584 & -0.012 \\
\hline & 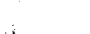 & $12-11$ & 362758.149 & $-0.321^{c}$ \\
\hline & $\therefore$ & $11-10$ & 362774.433 & $-0.106^{\mathrm{c}}$ \\
\hline & $11-10$ & $\mid 2-11$ & 362792.924 & $0.534^{\mathrm{c}}$ \\
\hline & & $11-10$ & 362882.501 & $0.262^{\mathfrak{c}}$ \\
\hline & & $10-9$ & 362846.059 & $0.260^{\mathrm{C}}$ \\
\hline \multirow[t]{6}{*}{$21 / 2-19 / 2$} & $11-10$ & $12-11$ & 363201.690 & $0.282^{\circ}$ \\
\hline & & $11-10$ & & \\
\hline & & $10-9$ & 363089.954 & -0.003 \\
\hline & $10-9$ & $11-10$ & 363067.876 & $-0.128^{\mathrm{c}}$ \\
\hline & & $10-9$ & 367086.823 & $-0.133^{c}$ \\
\hline & & $9-8$ & 367099.549 & 0.048 \\
\hline \multicolumn{5}{|l|}{$11_{39}-10_{38}$} \\
\hline \multirow{2}{*}{$23 / 2-21 / 2$} & & $12-11$ & 362260.169 & -0.036 \\
\hline & & $11-10$ & 362257.340 & 0.015 \\
\hline $21 / 2-19 / 2$ & & $11-10$ & 362715.725 & 0.038 \\
\hline & & $10 \sim 9$ & 362719.449 & 0.011 \\
\hline $11_{38}-10_{37}$ & & & & \\
\hline $23 / 2-21 / 2$ & & $12-11$ & 362265,340 & -0.030 \\
\hline & & $11-10$ & 362262.482 & -0.005 \\
\hline $21 / 2-19 / 2$ & & $11-10$ & 362720.561 & 0.041 \\
\hline & & $10-9$ & 362724.302 & -0.006 \\
\hline $11_{4}-10_{4}$ & & & & \\
\hline $23 / 2-21 / 2$ & $12-11$ & & $\begin{array}{l}361983.137 \\
361978155\end{array}$ & $\begin{array}{l}0.154^{c} \\
0.230^{c}\end{array}$ \\
\hline $21 / 2-19 / 2$ & $\begin{array}{l}11-10 \\
11-10\end{array}$ & & 362684.289 & 0.022 \\
\hline & $10-9$ & & 362690.489 & 0.037 \\
\hline $11_{5}-10_{5}$ & & & & \\
\hline $23 / 2-21 / 2$ & & $12-11$ & 361646.821 & -0.010 \\
\hline & & $11-10$ & 361638.884 & 0.024 \\
\hline $21 / 2-19 / 2$ & & $11-10$ & 362672.278 & $0.201^{\circ}$ \\
\hline
\end{tabular}

The complete list is deposited at E-PAPS (Ref. 17). Standard deviation of the fit is $25 \mathrm{kHz}$. Calculated frequencies were obtained from the nolecular constants given in Table III.

bresiduals in the fit. $\Delta v=v_{\text {obs }}-v_{\text {catc }}$

Not included in the fit.
TABLE II. Some observed and calculated transition frequencies of $\mathrm{CD}_{2} \mathrm{P}^{2}$

\begin{tabular}{|c|c|c|c|c|}
\hline$N_{K a K c}^{\prime},-N_{K a K c}$ & $J^{\prime}-I$ & $F^{\prime}-F$ & $v_{\text {obs }}$ & $\Delta v^{b}$ \\
\hline \multirow[t]{4}{*}{$9_{09}-8_{03}$} & $19 / 2-17 / 2$ & $10-9$ & 244721.285 & 0.016 \\
\hline & & $9-8$ & 244725.413 & 0.046 \\
\hline & $17 / 2-15 / 2$ & $9-8$ & 244880.845 & $0.098^{c}$ \\
\hline & & $8-7$ & 244875.377 & 0.035 \\
\hline \multirow{4}{*}{$9_{19^{-8}} 8_{18}$} & $19 / 2-17 / 2$ & $10-9$ & 239707.660 & 0.022 \\
\hline & & $9-8$ & 239709.880 & 0.036 \\
\hline & $17 / 2-15 / 2$ & $9-8$ & 239923.144 & $-0.132^{c}$ \\
\hline & & $8-7$ & 239924.581 & $-0.134^{c}$ \\
\hline \multirow[t]{2}{*}{$9_{18}-8_{17}$} & $17 / 2-15 / 2$ & $9-8$ & 251504.329 & $0.310^{c}$ \\
\hline & & $8-7$ & 251501.133 & $-0.181^{c}$ \\
\hline \multirow{4}{*}{$9_{28}-8_{27}$} & $19 / 2-17 / 2$ & $10-9$ & 245598.720 & $-0.197^{\circ}$ \\
\hline & & $9-8$ & 245615.570 & 0.001 \\
\hline & $17 / 2-15 / 2$ & $9-8$ & 245812.601 & $-0.653^{c}$ \\
\hline & & $8-7$ & 245833.546 & 0.025 \\
\hline $9_{36}-8_{35}$ & $19 / 2-17 / 2$ & $10-9$ & & \\
\hline \multirow{2}{*}{$9_{27}^{36}-826$} & & $10-9$ & 246725.315 & $-0.260^{c}$ \\
\hline & $17 / 2-15 / 2$ & $8-7$ & 246928.576 & $-0.288^{\mathrm{c}}$ \\
\hline \multirow{3}{*}{$9_{37}-8_{36}$} & $19 / 2-17 / 2$ & $10-9$ & 245813.799 & -0.016 \\
\hline & $17 / 2-15 / 2$ & $9-8$ & 246167.283 & 0.007 \\
\hline & & $8-7$ & 246174.998 & 0.014 \\
\hline \multirow{3}{*}{$9_{36}-8_{35}$} & $19 / 2-17 / 2$ & $9 \ldots 8$ & 245828.460 & $0.194^{c}$ \\
\hline & $17 / 2-15 / 2$ & 9.8 & 246185.878 & $-0.138^{c}$ \\
\hline & & $8-7$ & 246193.837 & -0.040 \\
\hline \multirow[t]{3}{*}{$9_{4}-8_{4}$} & $19 / 2-17 / 2$ & $9-8$ & 245690.529 & -0.002 \\
\hline & $17 / 2-15 / 2$ & $9-8$ & 246153.683 & 0.013 \\
\hline & & $8-7$ & 246166.274 & -0.004 \\
\hline
\end{tabular}

The complete list is deposited at E-PAPS (Ref. 17). Standard deviation of the fit is $36 \mathrm{kHz}$. Calculated frequencies were obtained from the molecular constants given in Table III.

${ }^{b}$ Residuals in the least-squares fit. $\Delta \nu=\nu_{\mathrm{ots}}-\nu_{\text {calc }}$

Not included in the least-sq̨uares fit.

where $H_{10}$ and $H_{35}$ represent the rotational Hamilonian and the spin rotation interaction Hamiltonian including centrifugal distortion effects, respectively. $H_{\mathrm{mh}}(X)$ denotes the Hamilonian for magnetic dipole dipole interaction of the nucleus $X$. The matrix elements of the Hamiltonian were derived by using the standard method ${ }^{14}$ with the basis function of $\mid N K S J I(P) F_{1} I(H$ or $\left.D) F M_{F}\right\rangle$ employing the coupling scheme of $J=N+S, F_{1}=J+I(\mathrm{P}), \quad l(\mathrm{H}$ or $\mathrm{D})$ $=I\left(\mathrm{H}_{1}\right.$ or $\left.\mathrm{D}_{1}\right)+I\left(\mathrm{H}_{2}\right.$ or $\left.\mathrm{D}_{2}\right)$, and $F=F_{1}+I(\mathrm{H}$ or D $)$. Leastsquares fitting programs were written for the analysis of the observed spectral lines. The program for $\mathrm{CH}_{2} \mathrm{P}$ is composed of two subroutines, for $I(\mathrm{H})=0$ and $l(\mathrm{H})=1$, whereas that of $\mathrm{CD}_{2} \mathrm{P}$, three subroutines for $l(\mathrm{D})=0, I(\mathrm{D})=1$, and $I(\mathrm{D})=2 .{ }^{15}$ The energy levels were calculated by direct diagonalization of the Hamiltonian marrices. The program was used to determine simultaneously most of the molecular constants related to Eq. (1), regardless of $K_{a}=$ even or odd.

Many line frequencies, partly unresolved for hyperfine structure and for higher $K$ doubling, were included in the fit using calculated frequencies by averaging the component frequencies that were expected to be included. This is because the hidden components were found to give a sizable frequency shift to the calculated line frequency. ${ }^{16}$ In the final least-squares fit were included 158 spectral lines from a total of 245 observed lines. The standard deviation of the fit was $25 \mathrm{kHz}$ and residuals between the observed and calculated frequencies are listed in Table $1 .{ }^{17}$ The determined molecular constants are given in Table III. The centrifugal distortion 
TABLE M. Molecular constants of $\mathrm{CH}_{2} \mathrm{P}$ and $\mathrm{CD}_{2} \mathrm{P}$ in the ${ }^{2} B_{2}$ ground electronic state (MHz)

\begin{tabular}{ccc}
\hline Constant & \multicolumn{1}{c}{$\mathrm{CH}_{2} \mathrm{P}$} & \multicolumn{1}{c}{$\mathrm{CD}_{2} \mathrm{P}$} \\
\hline$A_{0}$ & $296178.1(68)$ & $148439.3(39)$ \\
$B_{0}$ & $16967.1024(112)$ & $14312.5948(185)$ \\
$C_{0}$ & $16004.0274(110)$ & $13015.1040(151)$ \\
$\Delta_{N}$ & $0.0200909(67)$ & $0.01352397(180)$ \\
$\Delta_{N K}$ & $0.879592(139)$ & $0.49475(102)$ \\
$\Delta_{K}$ & $22.85^{b}$ & $5.043^{\mathrm{c}}$ \\
$\delta_{N}$ & $0.0012308(126)$ & $0.0014339(193)$ \\
$\delta_{K}$ & $0.6225(48)$ & $0.3504(55)$ \\
$\Phi_{N K}$ & $0.00000708(54)$ & $0.0000076(37)$ \\
$\Phi_{K N}$ & $-0.0001902(35)$ & $-0.000050(54)$ \\
$\epsilon_{a a}$ & $4220.56(24)$ & $2074.27(193)$ \\
$\epsilon_{b b}$ & $-8.334(51)$ & $-7.060(177)$ \\
$\epsilon_{c c}^{s}$ & $-295.533(52)$ & $-241.283(157)$ \\
$\Delta_{N}^{s}$ & $0.000740(67)$ & $-0.00023(32)$ \\
$\Delta_{K W}^{s}$ & $-0.0499(26)$ & $-0.017(23)$ \\
$\Delta_{K}^{s}$ & $-0.5885(178)$ & $0.199(153)$ \\
$a_{F}(\mathrm{P})$ & $177.263(58)$ & $173.08(149)$ \\
$T_{a a}(\mathrm{P})$ & $-341.77(21)$ & $-340.2(27)$ \\
$T_{b b}(\mathrm{P})$ & $607.84(189)$ & $601.3(37)$ \\
$C_{a a}(\mathrm{P})$ & $1.116(58)$ & $0.18(48)$ \\
$C_{b b}(\mathrm{P})$ & $\left.0.0^{\mathrm{d}}\right)$ & $0.0^{\mathrm{d}}$ \\
$C_{c c}(\mathrm{P})$ & $0.1345(92)$ & $-0.035(61)$ \\
$a_{F}(\mathrm{H})$ & $104.936(37)$ & \\
$T_{a d}(\mathrm{P})$ & $3.677(176)$ & \\
$T_{b b}(\mathrm{P})$ & $-7.69(135)$ & \\
\hline \hline
\end{tabular}

${ }^{2}$ alues in parentheses denote three times the standard deviation and apply to the last digits of the constants.

${ }^{b}$ Centrifugal distontion constant $\Delta_{K}$ from Ref. 18 .

${ }^{c}$ Centrifugal distortion constant $\Delta_{K}$ from Refs. 19 and 20 dFixed.

constant $\Delta_{K}$, which is not determinable from a-type rotational transitions only, was fixed at $22.85 \mathrm{MHz}$, to a value of a molecule similar in size $\left(\mathrm{CH}_{2} \mathrm{~S}\right) .^{18}$ In the initial stage of the anaiysis, three components of the phosphorus nuclear spin rotation coupling constants were included in the fit as determinable parameters, but $C_{b b}(P)$ was found to converge to a very small value around zero. Therefore, $C_{b b}$ was fixed at 0.0 in the later fits. For analysis of the spectral lines of $\mathrm{CD}_{2} \mathrm{P}$, the $\Delta_{K}$ parameter was fixed at $5.043 \mathrm{MHz}$, to the value for $\mathrm{CD}_{2} \mathrm{~S}_{0}{ }^{19,20}$ Since it was difficult to measure the hyperfine components due to the deuterium nuclei, as described in the Experiment, these were not included in the analysis. In the final fit, 70 spectral lines from 104 observed lines were used. The standard deviation of the fit was $36 \mathrm{kHz}$ and its residuals are listed in Table II. ${ }^{17}$ Many unresolved or overlapped lines giving unsymmetrical line shapes for both the species resulted in a large reduction of the line numbers used in the fits as indicated in Tables I and II. The molecular constants determined are given in Table III. The phosphorus nuclear spin rotation coupling constants and the centrifugal distortion terms of the spin rotation coupling constants were included in the analysis of $\mathrm{CD}_{2} \mathrm{P}$, as in the case of $\mathrm{CH}_{2} \mathrm{P}$, but their determined values are marginal as seen in Table III.

\section{DISCUSSION}

Small positive values of inertial defects derived from observed moments of inertia for $\mathrm{CH}_{2} \mathrm{P}$ and $\mathrm{CD}_{2} \mathrm{P}$ clearly
TABLE IV, Conparison of the structural parameters of $\mathrm{CH}_{2} \mathrm{P}$ with those of related molecules.

\begin{tabular}{|c|c|c|c|c|}
\hline Molecules & $r(\mathrm{CP})(\mathrm{A})$ & $r(\mathrm{CH})(\AA)$ & $\angle \mathrm{HCH}\left(^{\circ}\right)$ & Methods \\
\hline $\begin{array}{l}\mathrm{CH}_{2} \mathrm{P} \\
\exp \left(r_{0}\right)\end{array}$ & $1.6576(28)$ & $1.0912(61)$ & $115.96(96)$ & $M W^{2}$ \\
\hline$a b$ initio $\left(r_{t}\right)$ & 1.707 & 1.079 & 115.8 & $\begin{array}{l}\text { PMASDTQ/ } \\
6-31 G(d, p)^{b}\end{array}$ \\
\hline $\mathrm{CH}_{2} \mathrm{PH}\left(r_{0}\right)$ & $1.673(2)$ & $1.090(15)$ & $111.2(8)$ & $M W^{c}$ \\
\hline $\mathrm{CH}_{3} \mathrm{PH}_{2}\left(r_{g}\right)$ & $1.858(3)$ & $1.094(8)$ & & $\mathrm{ED}^{\mathrm{d}}$ \\
\hline $\mathrm{CP}\left(r_{e}\right)$ & $1.561977(7)$ & & & FTIR $^{c}$ \\
\hline $\operatorname{HCP}\left(r_{e}\right)$ & $1.54020(3)$ & $1.0666(2)$ & & $M W^{i}$ \\
\hline $\operatorname{MCCP}\left(r_{0}\right)$ & 1.685 & 1.057 & & $M W^{g}$ \\
\hline $\mathrm{CH}_{2} \mathrm{CP}\left(r_{e}\right)$ & $1.5889(10)$ & $1.0816(5)$ & $118.22(5)$ & $a b$ inisioh \\
\hline
\end{tabular}

Present study.

breference 8.

CReference 21.

dReference 24.

Reference 22

Reference 23.

Reference 5.

${ }^{\mathrm{h}} \mathrm{Reference} 6$.

show that the $\mathrm{CH}_{2} \mathrm{P}$ radical has a planar structure; $\Delta_{0}$ $=0.08609(8) \cup A^{2}$ for $C H_{2} R$ and $0.11549(18) u \AA^{2}$ for $\mathrm{CD}_{2} \mathrm{P}$. The $r_{0}$ structure of $\mathrm{CH}_{2} \mathrm{P}$ was determined from the observed rotational constants. Only three of the six moments of inertia are independent because of the planarity condition for the three moments of inertia of each species and the a component of the moments of inertia which is derived only from the $\mathrm{H}-\mathrm{H}$ distance. The $\mathrm{H}-\mathrm{H}$ distance was determined to be $1.840155(42) \AA$ where the figures in parentheses indicate $3 \sigma$ experimental errors, whereas the D-D distance was calculated to be $1.8386878(48) \AA$. The difference between the $\mathrm{H}-\mathrm{H}$ and $\mathrm{D}-\mathrm{D}$ distances originates from rotationvibration interaction giving an inertial defect. Therefore, three structural parameters of $\mathrm{CH}_{2} \mathrm{P}$ were ascertained from the observed moments of inertia of $\mathrm{CH}_{2} \mathrm{P}$ and $\mathrm{CD}_{2} \mathrm{P}$ by a least-squares fit. The structural parameters determined are $r_{0}(\mathrm{CP})=1.6576(28) \AA, \quad r_{0}(\mathrm{CH})=1.0912(61) \AA, \quad$ and $\angle \mathrm{HCH}=115.96(96)^{\circ}$, where values in parentheses indicate one sigma error, mainly due to the inertial defects of $\mathrm{CH}_{2} \mathrm{P}$ and $\mathrm{CD}_{2} \mathrm{P}$, giving $\sigma(\delta /)=0.0486 \mathrm{u}^{2}$, where $\delta I=I_{g g}^{o b s}$ $-I_{g g}^{\text {calc }}$. The determined structure is compared with its theoretically predicted result and also those of related molecules in Table IV. Comparison with theoretical values shows a significant difference in $r_{0}(\mathrm{CP}){ }^{8}$ The $\mathrm{CP}$ bond of $\mathrm{CH}_{2} \mathrm{P}$ is similar to those in $\mathrm{CH}_{2} \mathrm{PH}$ (Ref. 21) and HCCP, but quite different from those in $\mathrm{CP},{ }^{22} \mathrm{HCP}_{3}{ }^{23}$ and $\mathrm{CH}_{2} \mathrm{CP}$ (Ref. 6) which have a typical triple $\mathrm{C}=\mathrm{P}$ bond and that of $\mathrm{CH}_{3} \mathrm{PH}_{2}$ (Ref. 24) which has a typical single $\mathrm{C}-\mathrm{P}$ bond. If $\mathrm{CH}_{2} \mathrm{PH}$ is assumed to have a typical $\mathrm{CP}$ double bond, a small difference between the $\mathrm{CP}$ bond lengths of $\mathrm{CH}_{2} \mathrm{P}$ and $\mathrm{CH}_{2} \mathrm{PH}$ means that the $\mathrm{CP}$ bond of $\mathrm{CH} P$ has a small contribution from the CP triple bond.

The large Fermi contact term of the hydrogen nucleus could be explained by hyperconjugation of the $\sigma$ radical, as discussed in the case of $\mathrm{CH}_{2} \mathrm{~N} .{ }^{9}$ The $s$ character of the unpaired electron spin on the $\mathrm{P}$ nucleus was derived to be $1.3 \%$ from the observed $a_{F}(\mathrm{P})$ constant, where the atomic value was as given in Ref. 24 . Similarly the $s$ character on the hydrogen nuclei was calculated to be $7.3 \%$. The magnetic 
dipole-dipole coupling constant $T_{b b}(P)$ is almost equal to $-2 T_{a a}$ and $-2 T_{c c}$. This means that the unpaired electron occupies the $p_{\pi}$ orbital that extends to the $b$ principal axis of the molecule. When the $T_{b b}$ constant is compared with the atomic value ${ }^{25}$ the $p$ character at the $P$ nucleus is calculated to be $83.2 \%$. The summation of the spin densities at the $\mathrm{P}$ and $\mathrm{H}$ nuclei amounts to $99 \%$. The spin density obtained is consistent with the determined molecular structure given above; the $\mathrm{CP}$ double bond is somewhat modified by a small contribution of a $\mathrm{CP}$ triple bond corresponding to the hyperconjugation form.

There has been no information on the excited electronic states of $\mathrm{CH}_{2} \mathrm{P}$. Semiquantitative information is available from the observed spin-rotation coupling constant. ${ }^{26} \mathrm{CH}_{2} \mathrm{P}$ has a relatively large value of $\epsilon_{c c}$ which is characteristic of the $\sigma$ radical as exemplified in $\mathrm{CH}_{2} \mathrm{~N}^{9}{ }^{9}$ Since the $c$ component of the angular momentum belongs to $\mathrm{B}_{2}$ species in $C_{2 v}$ symmetry, the $\epsilon_{c c}$ constant is mainly responsible for spinorbit coupling to the excited states with $A_{1}$ symmetry. If one electron excitation is applied, the lowest $A_{1}$ state is estimated to be $50000 \mathrm{~cm}^{-1}$ above the ground electronic state. Similarly the lowest $B_{1}$ state is estimated to lie at $64000 \mathrm{~cm}^{-1}$ from the observed $\epsilon_{a a}$ constant.

Finally, the nuclear spin-rotation coupling constan $C_{a a}(\mathrm{P})$ was found to be relatively large, $1.116 \mathrm{MHz}$, which is comparable to its counterpart in $\mathrm{HPO},-1.12 \mathrm{MHz}{ }^{27}$ This $C_{a d}(\mathrm{P})$ constant is related to $a(\mathrm{P}) \epsilon_{a a} / A_{\text {so }},{ }^{28}$ where $a(\mathrm{P})$ is assumed to be $5 T_{b b} / 4$ and $A_{\text {so }}$ is calculated to be $229 \mathrm{~cm}^{-1}$ from the atomic value of $\zeta\left(3 p^{3}\right)$ for the phosphorus atom ${ }^{29}$ and the spin density obtained above. The $C_{a a}$ constant is estimated to be $0.468 \mathrm{MHz}$, which is less than half of the observed value.

In conclusion, the present study has established the existence of a new phosphorus-bearing radical $\mathrm{CH}_{2} \mathrm{P}$ in the gas phase for the first time by microwave spectroscopy, and characterized it to be a typical $\sigma$ radical like $\mathrm{CH}_{2} \mathrm{~N}$.

\section{ACKNOWLEDGMENT}

The authors thank Imtiaz K. Ahmad for her critical reading of the manuscript.

'I. K. Ahmad, H. Ozeki, and S. Saito, J. Chem. Phys. 110, 912 (1999).

${ }^{2}$ T. Hirao, S. Saito, and H. Ozeki, J. Chem. Phys. 105, 3450 (1996).

${ }^{3}$ J. A. Boatz, M. W. Schmidt, and M. S. Gordon, J. Phys. Chem. 91, 1743 (1987)

${ }^{4}$ M. T. Nguyen and T.K. Ha, Chem. Phys. 131, 245 (1989)

${ }^{5}$ I. K. Ahmad, H. Ozeki, and S. Saito, J. Chem. Phys. 107, 1301 (1997).

${ }^{6}$ I. K. Ahmad, H. Ozeki, S. Saito, P. Botschwina, J. Chem. Phys. 109, 4252 (1998).

${ }^{7}$ X. Endo and Y. Ohshima, J. Chem. Phys. 98, 6618 (1993).

${ }^{8}$ W. W. Schoeller and T. Busch. J. Mol. Struct: THEOCHEM 313, 27 (1994).

${ }^{9}$ S. Yamamoto and S. Saito, J. Chem. Phys. 96, 4157 (1992).

${ }^{10}$ M. Ohishi, D. McGonagle, W. M. Irvine, S. Yamamuto, and S. Saito. Astrophys. J. 427, L51 (1994)

${ }^{1}$ S. Yamamoto and S. Saito, J. Chem. Phys. 89, 1936 (1988).

${ }^{12}$ S. Saito and M. Goto, Astrophys. J. 410, L53 (1993).

${ }^{13}$ L. C. Bowater, J. M. Brown, and A. Carrington, Proc. R. Soc. London, Ser. A 313, 265 (1973)

${ }^{14}$ A. R. Edmonds, Angular Momentum in Quantum Mechanics (Princeton University Press, Princeton, 1957)

${ }^{15}$ T. Hirao, S. Hayakashi, S. Yamamoto, and S. Saito, J. Mol. Spectrosc. 187, $153(1998)$

${ }^{16}$ S. Saito, Y. Endo, and E. Hirota, Y. Mol. Spectrosc. 98, 138 (1983).

${ }^{17}$ See EPAPS Document No. E-JCPSA6-021941 for the observed and calculated transition frequencies for $\mathrm{CH}_{2} \mathrm{P}$ and $\mathrm{CD}_{2} \mathrm{P}$. This document may be retrieved via the EPAPS homepage (http//www.aip.org/pubservs/ epaps.html) or from ftp.aip.org in the directory /epaps/. See the EPAPS homepage for more information.

${ }^{18}$ D. J. Bedwell and G. Duxbury, J. Mol. Spectrosc. 84, 531 (1980).

${ }^{19}$ R. H. Judge and G. W. King, J. Mol. Spectrosc. 78, 51 (1979)

${ }^{20} \mathrm{P}$. H. Tumer, L. Halonen, and I. M. Mills, J. Mol. Spectrosc. 88, 402 (1981).

${ }^{21}$ H. W. Kroto, J, F. Nixon, and K. Ohno, J. Mol. Spectrosc. 90, 367 (1981).

${ }^{22}$ R. S. Ram and P. F. Bernath. J. Mol. Spectrosc. 122, 282 (1987).

${ }^{23}$ y. Lavigne and A. Cabana, Can. J. Phys. 60, 304 (1982)

${ }^{24}$ L. S. Bartell, J. Chem. Phys. 32, 832 (1960).

25 J. R. Morton and K. P. Preston, J. Magn. Reson. 30, 577 (1978).

${ }^{26}$ R. F. Curl Jr. Mol. Phys. 9, 585 (1965).

${ }^{27}$ S. Saito, Y. Endo, and E. Hirota, J. Chem. Phys. 84, 1157 (1986)

${ }^{28}$ Y. Endo, S. Saito, and E. Hirota, J. Mol. Spectrosc. 97, 204 (1983)

${ }^{29} \mathrm{H}$. LeFebvre-Brion and R. W. Field, Perturbations in the Spectra of Diatomic Molecules (Academic, Orlando, 1986). 